\title{
The Character strengths in organizations
}

\section{Incubator}

\author{
CHRISTOPHER PETERSON ${ }^{1 *}$ AND NANSOOK PARK ${ }^{2}$ \\ ${ }^{1}$ Department of Psychology, University of Michigan, Ann Arbor, Michigan, U.S.A. \\ ${ }^{2}$ Department of Psychology, University of Rhode Island, Kingston, Rhode Island, U.S.A.
}

\begin{abstract}
Summary Character refers to qualities within individuals that lead them to desire and to pursue the good. We propose that strengths of character are a neglected but critically important resource for organizations. Character matters because it leads people to do the right thing, and the right thing can be productive and profitable. Copyright (C) 2006 John Wiley \& Sons, Ltd.
\end{abstract}

\section{Introduction}

It is now common to hear calls for increased attention to character in work organizations as well as other social institutions, from government to education to sport. Character refers to those qualities within individuals that lead them to desire and to pursue the good (Baumrind, 1998). Moral goodness can be regarded as an ungrounded grounder, a value that needs no further justification, but our thesis here is different. Character matters in part because it leads people to do the right thing, and the right thing can be productive and profitable. Not only can nice guys finish first, but they often do finish first, by a number of criteria usually neglected by moral commentators. Our argument is not a cynical replacement of the ethical justification for good character but an additional rationale that legitimizes societal concern with character in an organizational context and how it can be encouraged.

\section{Background}

For the past several years, guided by the perspective of positive psychology, we have been involved in a project that conceptualizes, classifies, and measures strengths of character like curiosity, kindness, and leadership (Peterson \& Seligman, 2004). Our work stems from a long philosophical tradition that emphasizes virtues, dispositions to behave in morally praiseworthy ways, as opposed to the equally venerable tradition that focuses on moral rules or laws to be followed (Anscombe, 1958). As psychologists, we are more comfortable theorizing about dispositions as opposed to rules, because we thereby avoid the thorny question of the origin of such rules.

* Correspondence to: C. Peterson, Department of Psychology, University of Michigan, Ann Arbor, MI 48109-1109, U.S.A. E-mail: chrispet@umich.edu 
Our project is notable for several reasons. First, because moral goodness is complex, we approached good character as a family of positive traits, each of which exists in degrees. To convey the multidimensionality of character, we call its components character strengths. We arrived at this family of character strengths by identifying core virtues recognized across world cultures and throughout history and thinking of the different ways these are manifest (Dahlsgaard, Peterson, \& Seligman, 2005).

So, the core virtue of wisdom is comprised of cognitive strengths that entail the acquisition and use of knowledge: for example, creativity, curiosity, love of learning, and open-mindedness. The core virtue of courage consists of emotional strengths that involve the exercise of will to accomplish goals in the face of opposition, external or internal; for example, authenticity and honesty, bravery, persistence, and zest. The core virtue of humanity is made up of interpersonal strengths that involve "tending and befriending" others; for example, kindness, love, and social and emotional intelligence. The virtue of justice encompasses civic strengths that underlie healthy community life; for example, justice, leadership, and teamwork. Temperance entails strengths that protect against excess; for example, forgiveness, modesty, prudence, and self-regulation. Finally, the core virtue of transcendence subsumes a set of strengths that forge connections to the larger universe and provide meaning for the individual; for example, gratitude, hope, humor, and religiousness. Strengths of character that are arguably more culture-bound - like autonomy or competitiveness - are deliberately excluded from our classification, and conclusions of some generality can be drawn (Peterson \& Seligman, 2004).

Second, we devised measures of character strengths that have good reliability and promising validity. Quantitative comparisons and contrasts across different groups can be made. In addition, ipsative scoring of our measures allows identification of one's signature strengths and intra-individual comparisons. Our measurement work has been broad. To date, we have devised and evaluated several different methods: (a) focus groups to flesh out the everyday meanings of character strengths among different groups; (b) self-report questionnaires; (c) structured interviews; (d) informant reports of how target individuals rise to the occasion (or not) with appropriate strengths of character (e.g., openmindedness when confronting difficult decisions); and (e) case studies of nominated paragons of specific strengths. Among additional methods we are in the process of developing are: (f) a content analysis procedure for assessing character strengths from unstructured descriptions of self and others; and $(\mathrm{g})$ related strategies for scoring positive traits from archived material like obituaries or diaries. These latter methods extend the reach of future studies by allowing the investigation of good character among the otherwise unavailable. Furthermore, they permit longitudinal studies to be mounted retrospectively, so long as individuals have left behind suitable material for analysis.

Our self-report questionnaires and structured interviews may have some value in personnel selection and evaluation, not as a means to exclude people from an organization but to identify what they do well and then to tailor their roles to make best use of their particular assets (Clifton \& Harter, 2003). For example, someone with the strength of perspective, defined as the ability to offer wise counsel to others, might be asked to assume an official role as an ombudsperson or an unofficial role as a devil's advocate. Informant reports and content analyses can be easily used with existing methods of performance appraisal, again with the goal of describing what a worker does well.

\section{Findings to Date}

Given the availability of these measures, we have begun to explore the correlates and consequences of different components of good character, including those relevant in organizational settings. Here are some of our findings: 
- Particular strengths of character-gratitude, hope, zest, curiosity, and love - are robustly associated with life satisfaction as well as work satisfaction across a range of occupation types, from unskilled laborer to CEO (cf. Park, Peterson, \& Seligman, 2004). Although the link between satisfaction and productivity at work is complex, these findings imply the need for further attention to how character strengths and their consequences might be translated into good work performance. For example, Luthans and Jensen (2002) highlighted the importance of hope in sustaining the efforts of workers and organizations in an environment increasingly threatened by mergers, downsizing, bankruptcies, new technologies, an uncertain global economy, and terrorism. Hope is a strength that allows people to overcome uncertainty and to stay the course. So, in an ongoing prospective study of cadets at the US Military Academy, we are finding that the strength of hope predicts who stays in the service.

- We also have some hints that strengths of humanity contribute in particular to satisfaction with work that explicitly involves other people, like teaching or sales. Along these lines, in our study of cadets, we are learning that the strength of love predicts accomplishments as a leader. And in a study of teachers, we found that their social and emotional intelligence was associated with performance gains over the academic year on the part of their students.

- Students with the strengths of perseverance, prudence, and love earn better grades, even when ability test scores are held constant.

- The strength of hope is associated with good health, long life, and freedom from "accidents."

- The strength of zest is associated with regarding one's work as a calling (as opposed to a way to make money), a stance associated with desirable outcomes for individual workers as well as their employers, including increased work satisfaction, greater reluctance to retire, and fewer sick days (Wrzesniewski, McCauley, Rozin, \& Schwartz, 1997).

- Character strengths like gratitude and hope can be increased through simple exercises that have lasting effects on well-being to the degree that individuals incorporate the gist of the exercises into their ongoing lives (Seligman, Steen, Park, \& Peterson, 2005). Here is an important lesson for organizations that want to nurture strengths among their members. Special workshops or retreats can be important in highlighting and legitimizing a particular strength of character, but to make this strength part of everyday routine requires ongoing practice. Once established, character strengths can sustain themselves, but certainly not against the organizational grain. A workplace where rewards reflect a zero-sum scheme will not be one in which teamwork is readily displayed. And at the risk of stating the obvious, different strengths require different sorts of interventions. Because character is multidimensional, so too must be its encouragement.

\section{Topics for Further Study}

We have mentioned our decision to focus on character strengths that are ubiquitously recognized and valued, which means that our classification does not include all strengths of possible interest. Depending on the particular organization, strengths not in our classification deserve attention as well: for example, achievement and competition in sports and business, compassion and tolerance in religious groups, and duty and service in organizations infused by Confucian values. In an era of multinational corporations, recognition that different cultural groups bring different strengths of character to work is imperative. For example, U.S. workers are more likely to see work in terms of individual achievement, whereas Japanese workers are more likely to regard work as a social duty. Both 
are legitimate values, to be sure, but different strengths are brought to bear in their respective realization.

It is unlikely that any individual can "have it all" with respect to the components of good character. Tradeoffs among character strengths may not be inevitable, but empirically they occur. We find that strengths of the heart (e.g., gratitude and love) tend not to co-occur with strength of the head (e.g., perseverance and self-regulation) and that individually-focused strengths (e.g., curiosity and creativity) tend not to co-occur with other-focused strengths (e.g., teamwork and fairness). The practical implication is that we need to choose carefully the strengths we target in deliberate interventions because there may be unintended effects on other strengths.

In most of our work to date, we have assessed character strengths of individuals and linked them to outcomes for these same individuals. This strategy yields interesting results but overlooks what may be the most important consequence of good character: its effects on other people. We have found, for example, that the strength of self-regulation on the part of parents has a stronger relationship to the happiness of their children than it does to their own happiness. By implication, the payoff of other character strengths might be less in their individual impact than in their social impact, especially in an organizational setting.

We have also been interested in what we call organizational-level virtues: moral characteristics of the organization as a whole that go beyond simple summaries or composites of characteristics of the organization's individual members. As such, organizational-level virtues are an enduring part of the organizational culture. We have identified five widely-valued organizational virtues that cut across organizational schools and types, from workplaces to entire societies (Park \& Peterson, 2003):

- purpose-a shared vision of the moral goals of the organization, one reinforced by remembrances and celebrations; we suggest that the language of character strengths be used to articulate the moral aspects of corporate identity

- safety-protection against threat, danger, and exploitation that can undercut physical and psychological well-being; depression may be the most common disability in the Western world and is certainly the leading cause of lost productivity in the workplace (Stewart, Ricci, Chee, Hahn, \& Morganstein, 2003); any intervention that reduces depression among workers would pay for itself many times over (Langlieb \& Kahn, 2005), and the character-focused interventions that we have devised and tested decrease depression as they increase happiness (Seligman et al., 2005)

- fairness-equitable rules governing reward and punishment and the means for consistently enforcing them; this organizational-level virtue is a prerequisite for healthy competition and cooperation

- humanity - mutual care and concern, described by Kanov, Maitlis, Worline, Dutton, and Frost (2004) as collective compassion and hypothesized to have diverse benefits

- dignity - the treatment of all people in the organization as individuals regardless of their position; this organizational-level virtue is associated with increased employee autonomy and involvement and decreased mismanagement, abuse, and overwork

Our list is tentative at best, and further work is needed to finalize it. But once this process is complete, other questions can then be addressed. How can these virtues best be measured at the organizational level? What are the consequences of their presence or absence? Do they come into conflict with one another, and if so, how are conflicts adjudicated? How do organizational-level virtues develop? How are they sustained? And how do they enable the display of individual-level strengths of character?

"Enable" is a deliberately light-handed term, because the role of the moral organization in enabling good character on the part of its members is probably subtle. We speculate that a good organization can inspire its members to be more than they are-to reveal strengths of character that are dormant or to create new ones that allow them to rise to the occasions deemed important by the organization. 
In a study of the effects of the events of 9/11 on character strengths, we found that the theological virtues of St. Paul (faith, hope, and love) increased among Americans in the wake of the terrorist attacks; we concluded that crisis can be the crucible of character (Peterson \& Seligman, 2003). Less dramatic but certainly more typical is the enabling role played by moral organizations, and we suggest attention to how organizational practices can be engineered so that moral excellence and personal fulfillment on the part of all organizational members are afforded.

Corporation mission statements are replete with character language, but an organization must go beyond rhetoric to put its moral vision into action. Similarly, codes of professional ethics must do more than tell individuals what they should not do; they also need to tell people what they should do, in terms as concrete as possible (Handelsman, Knapp, \& Gottlieb, 2002). In short, attention to character strengths make discussions of corporate social responsibility more concrete and amenable to empirical research by providing a way to think about the actual people whose actions do or do not allow work organizations to move beyond a sole focus on profit and to pursue social and moral goals.

\section{Conclusion}

Character strengths are a resource largely untapped by typical organizations. We believe that people with good character are highly engaged in what they do and find significance beyond themselves in their activities. We believe that they are highly satisfied with their lives and that people who are highly satisfied are happier, healthier, more resilient, and more productive. Finally, we believe that strengths of character can be deliberately nurtured by institutional practices and norms that recognize, celebrate, and encourage the routinization of their display. We have preliminary evidence to back up all these assertions, but we have yet to test them simultaneously and prospectively in the same study of an actual work organization, using hard indices of performance and health, like sales records and health care utilization costs. We encourage our colleagues in organizational behavior to join us in the quest.

\section{Author biographies}

Christopher Peterson is Professor of Psychology at the University of Michigan. He received his PhD in social/personality psychology from the University of Colorado-Boulder and completed postdoctoral respecialization in clinical psychology at the University of Pennsylvania. He has a longstanding interest in personality and adaptation. His most recent project is a consensual classification of the character strengths and virtues that make possible the psychological good life.

Nansook Park is Associate Professor of Psychology at the University of Rhode Island. She received her MA in clinical psychology from Yonsei University, Seoul, Korea, and her $\mathrm{PhD}$ in school psychology from the University of South Carolina-Columbia. Using cross-cultural and developmental perspectives, she is investigating the structures, correlates, and consequences of positive experiences, life satisfaction, and character strengths, and especially their role in promoting positive development and resiliency among youth. 


\section{References}

Anscombe, G. E. M. (1958). Modern moral philosophy. Philosophy, 33, 1-19.

Baumrind, D. (1998). Reflections on character and competence. In A. Colby, J. James, \& D. Hart (Eds.), Competence and character through life (pp. 1-28). Chicago: The University of Chicago Press.

Clifton, D. O., \& Harter, J. K. (2003). Investing in strengths. In K. S. Cameron, J. E. Dutton, \& R. E. Quinn (Eds.), Positive organizational scholarship: Foundations of a new discipline (pp. 111-121). San Francisco: BerrettKoehler.

Dahlsgaard, K., Peterson, C., \& Seligman, M. E. P. (2005). Shared virtue: The convergence of valued human strengths across culture and history. Review of General Psychology, 9, 203-213.

Handelsman, M. M., Knapp, S., \& Gottlieb, M. C. (2002). Positive ethics. In C. R. Snyder, \& S. J. Lopez (Eds.), Handbook of positive psychology (pp. 731-744). New York: Oxford University Press.

Kanov, J. M., Maitlis, S., Worline, M. C., Dutton, J. E., \& Frost, P. J. (2004). Compassion in organizational life. American Behavioral Scientist, 47, 808-827.

Langlieb, A. M., \& Kahn, J. P. (2005). How much does quality mental health care profit employees? Journal of Occupational and Environmental Medicine, 47, 1099-1109.

Luthans, F., \& Jensen, S. M. (2002). Hope: A new positive strength for human resource development. Human Resource Development Review, 1, 304-322.

Park, N., \& Peterson, C. (2003). Virtues and organizations. In K. S. Cameron, J. E. Dutton, \& R. E. Quinn (Eds.), Positive organizational scholarship: Foundations of a new discipline (pp. 33-47). San Francisco: BerrettKoehler.

Park, N., Peterson, C., \& Seligman, M. E. P. (2004). Strengths of character and well-being. Journal of Social and Clinical Psychology, 23, 603-619.

Peterson, C., \& Seligman, M. E. P. (2003). Character strengths before and after September 11. Psychological Science, 14, 381-384.

Peterson, C., \& Seligman, M. E. P. (2004). Character strengths and virtues: A handbook and classification. New York: Oxford University Press/ Washington, DC: American Psychological Association.

Seligman, M. E. P., Steen, T. A., Park, N., \& Peterson, C. (2005). Positive psychology progress: empirical validation of interventions. American Psychologist, 60, 410-421.

Stewart, W. F., Ricci, J. A., Chee, E., Hahn, S. R., \& Morganstein, D. (2003). Cost of lost productive work time among US workers with depression. JAMA 289, 3135-3144.

Wrzesniewski, A., McCauley, C. R., Rozin, P., \& Schwartz, B. (1997). Jobs, careers, and callings: people's relations to their work. Journal of Research in Personality, 31, 21-33. 